\title{
Knowledge Level of Teachers of University of Agricultural Sciences, Bangalore on Information and Communication Technologies
}

\author{
Vinoda Shankara Naik* and N.S. Shivalinge Gowda
}

Department of Agricultural Extension, GKVK, UAS, Bangalore-560065

*Corresponding author

\section{A B S T R A C T}

The study was conducted to assess the knowledge level of the teachers working in the University of Agricultural Sciences Bangalore and this university consists of 4 campuses viz., College of Agriculture GKVK, College of Agriculture Hassan, College of Agriculture Mandya and College of sericulture, Chintamani. Population of the study consists of

Keywords

Knowledge gap,

Tools and

peripherals, Service

experience,

Information seeking pattern

\section{Article Info}

Accepted:

17 November 2019

Available Online:

10 December 2019 teachers, researchers and extension personnel working in UAS-Bangalore. Proportionate random sampling method was employed for selecting the sample. Thus the total sample size was 45. Ex-post-facto research design was followed. Data was collected through personal interview method and using questionnaires. Findings of the study revealed that as high as 40.00 per cent of the teachers belonged to medium knowledge level category. About 16 per cent of assistant professor belonged to medium knowledge category compared to professor (13.33\%) and associate professor (11.11\%). Further, results showed that the ranks assigned to the different dimensions based on percentage of scores obtained by the respondents viz., Tools and peripherals was assigned I rank while mobile applications and programmes were assigned II and III rank, respectively. Correlation analysis showed that age, service experience and awareness had significant relationship with the knowledge level of teachers on ICTs. The stepwise regression analysis revealed that the information seeking pattern, rural urban background and mass media exposure put together expressed 83.30 per cent of variation in knowledge level. Comparison of beta values revealed that information seeking pattern had significant and highest effect on knowledge level of teachers. There is great potential to improve the knowledge level among teachers on ICTs at UAS, Bangalore.

\section{Introduction}

Agricultural education is the basic foundation for developing manpower for research, education, extension and other allied sectors. It provides information and new technologies to the farming community to enable them to improve their productivity. The agriculture education is dynamic which needs timely dissemination of the latest knowledge. Information is being generated and updated across the globe from time to time. In the fast emerging of information explosion, it is very essential to access particular information without wasting time. According to UNESCO, Information and Communication Technology can be broadly understood as the technologies that facilitate communication, processing and 
transmission of information by electronic means. Information and communication technology (ICT) is currently an integral part in many aspects of human life. Over the years, education is also an aspect of life which gains massive benefits from the utilization of technology. The use of computers has enhanced in the development of new technologies, especially through internet With ICT, borderless information is rapidly transmits, which is much needed in the present education system, and thus it is the best tool to assist current teaching and learning (Drier, 2001).

The Information and Communication Technology (ICT) gives the possible solution because of its great potential in facilitating the search of required information easily and quickly. Therefore, the development of mastery on utilization of ICTs is one of vital requirements for the faculty to perform better in teaching, research and extension fields. The advantages of using ICTs are the timely availability of information, provides required information quickly, easier search, hyperlinks, $24 \times 7$ availability, easy storage and retrieval of information. So there is a need to explore the present status of the knowledge on ICTs of teachers of University of Agricultural Sciences Bangalore.

\section{Materials and Methods}

The study was conducted at University of Agricultural Sciences Bangalore and this university consists of 4 campuses viz., College of Agriculture GKVK, College of Agriculture Hassan, College of Agriculture Mandya and College of sericulture, Chintamani. Population of the study consists of teachers, researchers and extension personnel working at respective colleges. Teachers were considered from teaching campuses, researchers were considered from Agricultural Research Stations (ZARS/MARS) and extension personnel working at KVKs and other extension units of directorate of extension were considered. Proportionate random sampling method was employed for selecting the sample. Thus the total sample size was 45 (details of selection of sample was given below). Ex-post-facto research design was followed. Data was collected through personal interview method and using questionnaires. The collected data was analyzed by using mean, standard deviation, frequency, percentage, correlation, stepwise regression, etc.

After discussing with teachers 51 Information and Communication technologies were selected. This 51 ICTs were broadly grouped under 11 headings namely tools and peripherals, programmes, web browsers, search engines, personal mails, mobile applications, websites and data bases related to agriculture, social networking sites, conferencing, short message services and online transaction applications. Further, Knowledge on ICTs was measured by using five point continuum namely, very high, high, medium, less and very less/no knowledge with scores 5,4,3,2 and 1, respectively. So, Maximum and minimum scores of an individual were 255 and 51. Higher score reveals the respondent is having higher knowledge on ICTs. Further, based on the total score of knowledge the respondents were classified into three categories such as low, medium and high by considering mean and standard deviation as a measure of check. The procedure followed by Satya Gopal (2017) with slight modification was used.

\section{Results and Discussion}

It is clear from Table 1 that, as high as 40.00 per cent of the teachers belonged to medium knowledge level category, while 31.11 per cent and 28.89 per cent of the teachers were belonged to low and high knowledge on 
Information and Communication Technologies category, respectively. This is due to the knowledge possessed by the respondents was not helping them to use modern ICT tools because they lack specific operational knowledge and training about ICTs. A considerable percentage of respondents belonged to the medium knowledge category followed by low and high and such results were also reported by Nagalakshmi (2007).

The Knowledge level among the teachers of University of Agricultural Sciences Bangalore on ICTs as shown in Table 2 indicated that about 16 per cent of assistant professor belonged to medium knowledge category compared to professor (13.33\%) and associate professor $(11.11 \%)$. The data further revealed that 15.56 per cent professor were having low knowledge of ICT compare to which 8.89 per cent were assistant professor and 6.67 per cent were associate professor. On the other hand 13.33 per cent of assistant professor were belonged to high knowledge category compared to professor $(11.11 \%)$ and associate professor $(4.44 \%)$. Further, this table depicted that percentage of scores obtained for knowledge was 53.43 and per cent knowledge gap among teachers was 46.57. This is due tothe positive attitude towards the use of ICT by the teachers (Teo, 2008; Ndibalema, 2014) and their efforts should be made to ensure availability of ICT facilities and an environment in which ICT can be used frequently and effectively (Cubukcuoglu, 2013). The chi square value was 1.647 which is found to have a non-significant association between professor, associate professor and assistant professor with knowledge level. It is cleared that knowledge level is independent of designation of teachers.

An insight into the Table 3 revealed that the dimension wise knowledge level on Information and Communication
Technologies among the teachers of University of Agricultural Sciences Bangalore. The results indicated that the percentage of score obtained by tools and peripherals was 61.63 indicating the percent knowledge gap of 38.37. Mobile applications showed the second highest (36.81) percentage of score which indicated percent knowledge gap of 63.19. Whereas, programmes and social networking sites showed the third (30.67) and Fourth (26.67) highest percent scores which indicated the percentage knowledge gap of 69.33 and 73.33, respectively. Similarly, websites and databases related to agriculture (20.44), Online transaction applications (19.63), personal mails (8.93), web browsers (6.78), search engines (6.59), Conferencing (6.41) and short message services (2.52) indicating a percent knowledge gap of $79.56,80.37,91.07,93.22$, 93.41,93.59 and 97.48, respectively.

Further table shows that the ranks assigned to the different dimensions based on percentage of scores obtained by the respondents. Tools and peripherals was assigned I rank while mobile application and programmes were assigned II and III rank, respectively. Social networking sites and databases related to agriculture obtained the rank of IV and V, whereas online transactions applications, personal mails, web browsers, search engines, conferencing and short message services were assigned the VI,VII,VIII, IX, X and XI and respectively. The reason might be that, some of the ICTs are simple and can be used easily. Also respondents had low level of basic ICT knowledge and only half of them are familiar with the basic ICT terminologies which results in the increasing the knowledge gap was reported by Melisachew et al., (2010).

The data presented in Table 4 depicts that variables such as education, gender, number of publication, time spent in using ICTs, international exposure, rural-urban 
background, infrastructure and other resource facilities, scientific collaboration, academic performance, attitude, information seeking pattern, mass media exposure, innovative proneness, job commitment, job satisfaction, achievement motivation and training undergone were non significantly related with knowledge level on ICTs of teachers. Whereas, the variable like service experience had negative and significant relationship with knowledge level of the respondents at 1.00 per cent level of significance.

\section{Details of selection of Sample}

\begin{tabular}{|c|c|c|c|c|}
\hline Sl.No. & $\begin{array}{l}\text { UAS Bangalore and } \\
\text { constituent campuses }\end{array}$ & $\begin{array}{l}\text { No. of } \\
\text { respondents } \\
\text { allotted to each } \\
\text { campus }\end{array}$ & Division & $\begin{array}{c}\text { Number of } \\
\text { respondentsselected }\end{array}$ \\
\hline \multirow{3}{*}{1} & \multirow{3}{*}{ GKVK campus } & \multirow{3}{*}{18} & Teaching & 8 \\
\hline & & & Research & 6 \\
\hline & & & Extension & 4 \\
\hline & & & Total & 18 \\
\hline \multirow{3}{*}{2} & \multirow{3}{*}{ Hassan campus } & \multirow{3}{*}{9} & Teaching & 4 \\
\hline & & & Research & 3 \\
\hline & & & Extension & 2 \\
\hline & & & Total & 9 \\
\hline \multirow{3}{*}{3} & \multirow{3}{*}{ Mandya campus } & \multirow{3}{*}{9} & Teaching & 4 \\
\hline & & & Research & 3 \\
\hline & & & Extension & 2 \\
\hline \multirow{6}{*}{4} & & & Total & 9 \\
\hline & \multirow{3}{*}{ Chintamani campus } & \multirow{3}{*}{9} & Teaching & 4 \\
\hline & & & Research & 3 \\
\hline & & & Extension & 2 \\
\hline & & & Total & 9 \\
\hline & & \multicolumn{2}{|c|}{ Total sample size } & 45 \\
\hline
\end{tabular}

Table.1 Knowledge level of teachers on Information and Communication Technologies at University of Agricultural Sciences Bangalore

$(n=45)$

\begin{tabular}{|l|l|c|c|}
\hline SI. No. & \multicolumn{1}{|c|}{ Category } & \multicolumn{2}{|c|}{ Faculty } \\
\cline { 3 - 4 } & & Frequency & \% \\
\hline $\mathbf{1}$ & Low $(<123.96)$ & 14 & 31.11 \\
\hline $\mathbf{2}$ & Medium $(123.96-148.53)$ & 18 & 40.00 \\
\hline $\mathbf{3}$ & High $(>148.53)$ & \multicolumn{2}{|c|}{ SD=24.57 } \\
\hline & \multicolumn{1}{|c|}{ Mean= 136.24 } & \multicolumn{2}{|c|}{$\mathbf{5 3 . 4 3}$} \\
\hline & Percentage of scores obtained & $\mathbf{4 6 . 5 7}$ \\
\hline & Percent Knowledge gap & \multicolumn{2}{|c|}{} \\
\hline
\end{tabular}


Table. 2 Knowledge level among the teachers on Information and Communication Technologies at University of Agricultural Sciences Bangalore

\begin{tabular}{|c|c|c|c|c|c|c|c|c|}
\hline & & & & & & & \multicolumn{2}{|c|}{$(n=45)$} \\
\hline \multirow{3}{*}{$\begin{array}{l}\text { Sl. } \\
\text { No }\end{array}$} & \multirow[t]{3}{*}{ Category } & \multicolumn{6}{|c|}{ Faculty } & \multirow{3}{*}{$\begin{array}{c}\text { Chi } \\
\text { square }\end{array}$} \\
\hline & & \multicolumn{2}{|c|}{ Professor } & \multicolumn{2}{|c|}{$\begin{array}{l}\text { Associate } \\
\text { Professor }\end{array}$} & \multicolumn{2}{|c|}{$\begin{array}{l}\text { Assistant } \\
\text { Professor }\end{array}$} & \\
\hline & & Frequency & $\%$ & Frequency & $\%$ & Frequency & $\%$ & \\
\hline 1 & Low $(<123.96)$ & 7 & 15.56 & 3 & 6.67 & 4 & 8.89 & \multirow{3}{*}{$1.647^{\mathrm{NS}}$} \\
\hline 2 & $\begin{array}{l}\text { Medium (123.96 - } \\
148.53)\end{array}$ & 6 & 13.33 & 5 & 11.11 & 7 & $\begin{array}{c}15.5 \\
6\end{array}$ & \\
\hline 3 & High $(>148.53)$ & 5 & 11.11 & 2 & 4.44 & 6 & $\begin{array}{c}13.3 \\
3\end{array}$ & \\
\hline \multicolumn{4}{|c|}{ Mean=136.24 } & \multicolumn{5}{|c|}{$\mathrm{SD}=\mathbf{2 4 . 5 7}$} \\
\hline
\end{tabular}

Table.3 Dimension wise knowledge level on Information and Communication Technologies among the teachers of University of Agricultural Sciences Bangalore

\begin{tabular}{|c|l|c|c|c|c|c|}
\hline $\begin{array}{l}\text { SI. } \\
\text { No. }\end{array}$ & $\begin{array}{l}\text { Dimensions of } \\
\text { Information and } \\
\text { Communication } \\
\text { Technologies(ICTs) }\end{array}$ & $\begin{array}{l}\text { Maximum } \\
\text { Score }\end{array}$ & $\begin{array}{l}\text { Mean } \\
\text { score } \\
\text { obtained }\end{array}$ & $\begin{array}{l}\text { Percentage } \\
\text { of scores } \\
\text { obtained }\end{array}$ & $\begin{array}{l}\text { Percent } \\
\text { Knowledge } \\
\text { gap }\end{array}$ & Rank \\
\hline $\mathbf{1}$ & Tools and peripherals & 60 & 36.98 & 61.63 & 38.37 & I \\
\hline $\mathbf{2}$ & Mobile Applications & 50 & 22.09 & 36.81 & 63.19 & II \\
\hline $\mathbf{3}$ & Programmes & 35 & 18.40 & 30.67 & 69.33 & III \\
\hline $\mathbf{4}$ & $\begin{array}{l}\text { Social networking } \\
\text { sites }\end{array}$ & 30 & 16.00 & 26.67 & 73.33 & IV \\
\hline $\mathbf{5}$ & Websites and & 25 & 12.27 & 20.44 & 79.56 & V \\
\hline & $\begin{array}{l}\text { databases related to } \\
\text { Agriculture }\end{array}$ & & & & & \\
\hline $\mathbf{6}$ & $\begin{array}{l}\text { Online transaction } \\
\text { applications }\end{array}$ & 20 & 11.78 & 19.63 & 80.37 & VI \\
\hline $\mathbf{7}$ & Personal Mails & 10 & 5.36 & 8.93 & 91.07 & VII \\
\hline $\mathbf{8}$ & Web Browsers & 5 & 4.07 & 6.78 & 93.22 & VIII \\
\hline $\mathbf{9}$ & Search Engines & 5 & 3.96 & 6.59 & 93.41 & IX \\
\hline $\mathbf{1 0}$ & Conferencing & 10 & 3.84 & 6.41 & 93.59 & X \\
\hline $\mathbf{1 1}$ & Short Message & 5 & 1.51 & 2.52 & 97.48 & XI \\
& Services & & & & & \\
\hline
\end{tabular}


Table.4 Relationship between knowledge level on Information and Communication Technologies with socio-economic characteristics of teachers of University of Agricultural Sciences Bangalore

\begin{tabular}{|c|l|c|}
\hline Sl. No. & \multicolumn{1}{|c|}{ Independent variables } & ' ${ }^{\prime}$ 'value \\
\hline $\mathbf{1}$ & Age & $-0.365^{*}$ \\
\hline $\mathbf{2}$ & Education & 0.085 \\
\hline $\mathbf{3}$ & Gender & 0.193 \\
\hline $\mathbf{4}$ & Number of publications & -0.247 \\
\hline $\mathbf{5}$ & Time spent in using ICTs & 0.245 \\
\hline $\mathbf{6}$ & International Exposure & -0.131 \\
\hline $\mathbf{7}$ & Service experience & -0.433 \\
\hline $\mathbf{8}$ & Rural-urban background & -0.007 \\
\hline $\mathbf{9}$ & Infrastructure and other resource facilities & -0.078 \\
\hline $\mathbf{1 0}$ & Scientific collaboration & -0.047 \\
\hline $\mathbf{1 1}$ & Academic performance & -0.078 \\
\hline $\mathbf{1 2}$ & Attitude & 0.216 \\
\hline $\mathbf{1 3}$ & Awareness & $0.875^{* *}$ \\
\hline $\mathbf{1 4}$ & Information seeking pattern & -0.162 \\
\hline $\mathbf{1 5}$ & Mass media exposure & -0.205 \\
\hline $\mathbf{1 6}$ & Innovative proneness & 0.039 \\
\hline $\mathbf{1 7}$ & Job commitment & -0.142 \\
\hline $\mathbf{1 8}$ & Job satisfaction & 0.001 \\
\hline $\mathbf{1 9}$ & Achievement motivation & 0.015 \\
\hline $\mathbf{2 0}$ & Training undergone & 0.065 \\
\hline $\mathbf{S}$ & a & \\
\hline & & \\
\hline
\end{tabular}

**Significant at the 0.01 level

* Significant at the 0.05 level 
Table.5 Extent of contribution of independent variables to knowledge level on Information and Communication Technologies of teachers of University of Agricultural Sciences Bangalore

$(n=45)$

\begin{tabular}{|c|c|c|c|c|}
\hline $\begin{array}{l}\text { Sl. } \\
\text { No. }\end{array}$ & Independent variables & $\begin{array}{l}\text { Regression co- } \\
\text { efficient (b) }\end{array}$ & $\begin{array}{c}\text { Standard } \\
\text { error }\end{array}$ & 't' value \\
\hline 1 & Age & 0.014 & 0.480 & 0.030 \\
\hline 2 & Education & -4.308 & 4.350 & -0.990 \\
\hline 3 & Gender & -2.363 & 4.630 & -0.510 \\
\hline 4 & Number of publications & -0.095 & 0.034 & -2.821 \\
\hline 5 & Time spent in using ICTs & 0.401 & 1.311 & 0.306 \\
\hline 6 & International Exposure & -3.140 & 1.926 & -1.630 \\
\hline 7 & Service experience & -0.566 & 0.590 & -0.960 \\
\hline 8 & Rural-urban background & -1.483 & 0.998 & -1.486 \\
\hline 9 & $\begin{array}{l}\text { Infrastructure and other } \\
\text { resource facilities }\end{array}$ & -0.093 & 0.885 & -0.105 \\
\hline 10 & Scientific collaboration & 0.280 & 0.905 & 0.309 \\
\hline 11 & Academic performance & 0.141 & 0.063 & 2.230 \\
\hline 12 & Attitude & -0.703 & 0.416 & -1.691 \\
\hline 13 & Awareness & 3.406 & 0.296 & 11.509 \\
\hline 14 & Information seeking pattern & -0.574 & 0.768 & -0.747 \\
\hline 15 & Mass media exposure & 0.591 & 1.407 & 0.420 \\
\hline 16 & Innovative proneness & 1.312 & 0.898 & 1.461 \\
\hline 17 & Job commitment & 3.425 & 1.859 & 1.843 \\
\hline 18 & Job satisfaction & -0.030 & 0.194 & -0.153 \\
\hline 19 & Achievement motivation & 2.859 & 1.048 & 2.730 \\
\hline 20 & Training undergone & -0.856 & 0.785 & -1.091 \\
\hline
\end{tabular}

Table.6 Stepwise regression analysis to identify the extent of contribution of independent variables to knowledge level on Information and Communication Technologies of teachers

$(n=45)$

\begin{tabular}{|c|c|c|c|c|}
\hline $\begin{array}{c}\text { Sl. } \\
\text { No. }\end{array}$ & \multicolumn{1}{|c|}{ Independent variables } & Beta & $\begin{array}{c}\text { Regression co- } \\
\text { efficient (b) }\end{array}$ & 't' value \\
\hline $\mathbf{1}$ & Information seeking pattern & 0.801 & 3.045 & $12.584 * *$ \\
\hline $\mathbf{2}$ & Rural urban background & -0.284 & -0.737 & $-4.426^{* *}$ \\
\hline $\mathbf{3}$ & Mass media exposure & -0.128 & -0.879 & $-2.021 *$ \\
\hline
\end{tabular}


Further, data in table also indicates that, the variable like age had negative significant relationship with knowledge level of the respondents at 5.00 per cent level of significance. Further, data in the table also showed that awareness had positive and significant relationship with knowledge level of the respondents at 1.00 per cent level of significance. Janaka (2016) was also explained the relationship between knowledge level on ICTs and personal profile of faculty.

Multiple regression analysis was carried out to determine the extent of contribution made by the independent variables and to identify those variables which contribute significantly to the Knowledge level on ICTs. The results of multiple regression analysis are presented in Table 5.A careful observation of the data indicated that the ' $F$ ' value (13.164) obtained from the multiple regression analysis was found to be statistically significant at one per cent level of probability indicating that all the independent variables put together exerted significant influence in knowledge level of teachers on ICTs. The co-efficient of determination $\left(\mathrm{R}^{2}\right)$ was 0.916 which indicated that 91.60 per cent of variation in knowledge level of teachers on ICTs was together explained by all the independent variables. But, none of the variables found significant. So, to determine the significant independent variables and its contribution the stepwise regression analysis was employed. The stepwise regression was applied so that the specification bias of the model does not occur. The results presented in the Table 6 revealed that the fitted model is adequate in explaining the variation in the knowledge level of teachers as indicated by a high and significant coefficient of multiple determinations0.833. In other words, 83.30 per cent of the variation is expressed by the factors included in the model. The standardized regression coefficient has been computed from the original 'b' coefficients, so that they can be compared across the factors to assess the magnitude of effect.

It could be observed from the table that the Information seeking pattern had the powerful effect (0.801) on teachers knowledge, influencing in positive direction. Interestingly, rural urban background and mass media participation influenced the teachers knowledge negatively and significantly.

Comparison of beta values revealed that information seeking pattern had significant and highest effect on knowledge level of teachers. This might be due to information seeking ability leads to obtain information in both human and technological contexts. So information seeking ability is high individual possesses higher operational knowledge. Thus, information seeking pattern has emerged as a significant factor influencing knowledge level of teachers. Whereas negative influence of rural urban background and mass media exposure is probably due to type of education, unavailability of mass medias and inadequate transport facilities available to the teachers to access ICTs.

It can be concluded from this study that as high as 40.00 per cent of the teachers belonged to medium knowledge level category and the per cent knowledge gap was 46.57. Overall the teachers are in the medium to high knowledge $(68.89 \%)$ category but still there is a scope to improve the knowledge level of the teachers working in teaching, research and extension wing at University of Agricultural Sciences Bangalore. The findings reinforce the theory of the role and contribution of knowledge in enhancing ICT application among teachers. Practically, it can be implicated that teachers' ICT knowledge need to be increased. So there is need to equip university and their faculty with adequate infrastructure and skills. This will enable to 
take teaching, research and extension in Agricultural University to a greater height.

\section{References}

Cubukcuoglu, B., 2013, Factors enabling the use of technology in subject teaching. International Journal of Education and Development using Information and Communication Technology, Vol. 9(3): 50-60.

Drier, H.S. 2001.Teaching and learning mathematics with interactive spreadsheets. School Science and mathematics, 101(4): 170-179.

Janaka, I. G. K., 2016, Usage pattern of eresources by the faculty of university of agricultural sciences, Dharwad. M.Sc. (Agri.) thesis (unpub.), University of Agricultural Sciences, Dharwad.

Melisachew, A., Lemma, L. and Solomon, S., 2010, Knowledge, Attitude and Utilization of Information Communication Technologies (ICTs) in an Ethiopian Medical Teaching Hospital. BMC Medical Informatics and
Decision Making, Vol, 13(31): 4-8.

Nagalakshmi, C., 2007, Integrating ICT with multiple functions for agriculture development. MSc. (Agri.) thesis (unpub.), University of Agricultural Sciences, Bangalore.

Ndibalema, P., 2014, Teacher attitudes towards the use of Information Communication Technology (ICT) as a pedagogical tool in secondary schools in Tanzania: The case of Kondoa district. International Journal of Education and Research, Vol. 2(2): 410.

Satya Gopal., 2017, Information and Communication Technology (ICT) utilization in agricultural educationGap analysis. Report submitted to ICAR by department of agricultural extension, S.V. agricultural college, Tirupati.

Teo, T., 2008, Pre-service teachers attitude towards computer use: A Singapore survey. Australian Journal of Educational Technology, Vol. 23(4): 45-53.

\section{How to cite this article:}

Vinoda Shankara Naik and Shivalinge Gowda, N.S. 2019. Knowledge Level of Teachers of University of Agricultural Sciences, Bangalore on Information and Communication Technologies. Int.J.Curr.Microbiol.App.Sci. 8(12): 2465-2473.

doi: https://doi.org/10.20546/ijcmas.2019.812.290 